at the boiling point while the surface is little more than lukewarm. The features of this kettle are (1) that the water in making its way to the tap passes through the hot zone where it is exposed to the full effect of the source of heat; and (2) that cold water may be added slowly at the top without lowering the temperature of the hot water which is being drawn off at the time. The prompt supply obtainable in this way is for many purposes a great advantage. The kettles are of a cylindrical shape with a flat lid, as shown in the illustration, and present no difficulties or complications in their management. Half-gallon, one-gallon, and two-gallon sizes are made for domestic use, to be heated over gas jets, oil stoves, open fires, or kitchen ranges. The half-gallon size is five inches high and seven and a half inches in diameter; the prices are $2 s .9 d$. in tinned steel plate and $5 s, 6 d$. in copper. Larger sizes for supplying baths and for other purposes are also to be obtained. The manufacturers are the Boiler Heater Co., 46, Queen Victoriastreet, London, E. C.

\section{AN IMPROVED TARSAL CYST FORCEPS.}

Messrs. Weiss and Son have made for me an eyelid clamp for use in operating on tarsal cysts which, I venture to think, is an improvement on any other and from an extended trial I am satisfied as to its handiness and usefulness. Fig. 1 gives a general idea of its size and construction. The blades are detachable and the instrument can be obtained with the

FIG. 1.

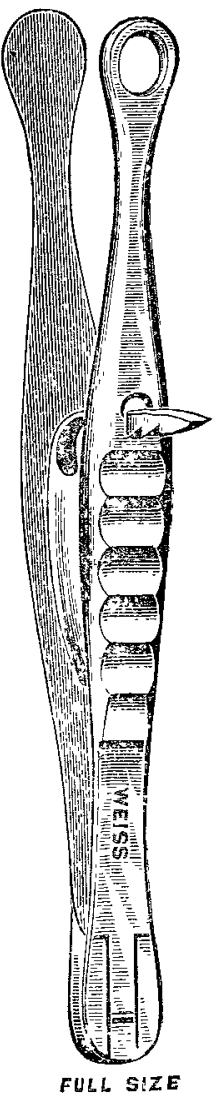

FIG. 2.

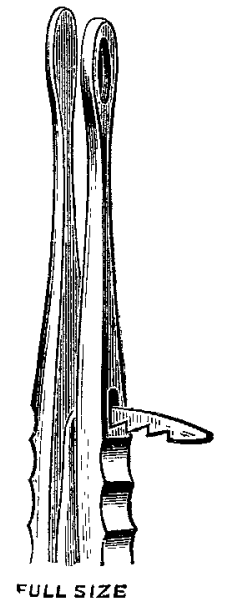

opening in the female blade either nine millimetres or six millimetres in diameter. For hospital use I would advise the former. Fig. 2 shows the space between the blades when they are clamped as closely as possible, which admits of the eyelid being firmly held without being unduly pressed and bruised.

JOHN R. ROLSTON, Surgeon, Royal Eye Infirmary, Plymouth; Ophthalmic
Surgeon, Royal Albert Hospital, Plymouth.

\section{"COMBINATIONS" TEST TYPE.}

THESE are to be used with a mirror at three metres. The cabinet is placed on a low table and the patient stands immediately behind with the test glasses between him and the cabinet. If he complains of inability to read small type but sees well in the distance the examiner puts his finger on a letter of $\frac{6}{6}$ and whilst the patient looks in the mirror he simply asks, "What is this?" and turns the cube to test the patient's accuracy. If near and distant vision are defective the examiner puts a finger on $\frac{6}{18}$. If the patient complains that he cannot see in the distance but can see to read well the finger is placed on $\frac{6}{60}$. We have used them at the Croydon Hospital for 12 months and find that they save from 40 to 60 per cent. of the words used in examination and at least from 60 to 70 per cent. of the time. We have used the rotatory box before these but now it is never used. Unquestionably the new test type saves time and energy

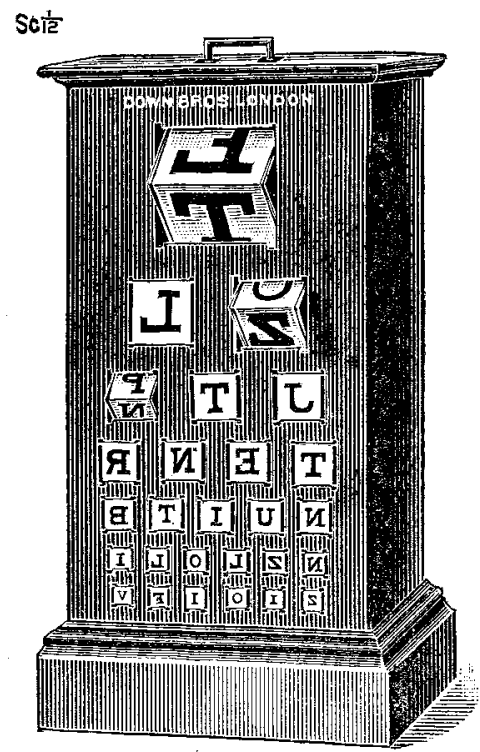

and is a great aid to accuracy when dealing with unreliable patients, such as children and senile patients. Moreover, the examiner can show four letters in $\frac{6}{60}, 16$ combinations in $\frac{6}{36}, 64$ in $\frac{8}{24}, 256$ in $\frac{6}{1}, 1024$ in $\frac{6}{12}, 2048$ in $\frac{6}{9}$, and so on, the type therefore being unlearnable.

Messrs. Down Bros., Limited, St. Thomas's-street, Borough, London, are the makers.

Croydon.

Charles Wray, F.R.C.S. Eng.

St. Bartholomew's Hospital and Medical ScHOOL. - Sir William S. Church, President of the Royal College of Physicians of London, distributed the prizes on July 15th to the students at St. Bartholomew's Hospital Medical School in the great hall of the hospital. Sir Trevor Lawrence, treasurer of the hospital, presided and there was a large attendance.-Mr. W. D. Harmer (the Warden), in his report on the work of the school during the past year, said that its prosperity had been fully maintained. 'The number of students who entered was 129 , as against 140 in the previous year, and the total number of students who had been working at the hospital was 573. St. Bartholomew's Hospital still headed the list among the metropolitan schools in regard to the number of students who entered for the full course. Various changes had taken place in the hospital staff, among them being the retirement of Sir William Church from the active staff, of which he had been a member for 35 years, and his appointment as consulting physician. Sir Trevor Lawrence then addressed the gathering and said that it was necessary to have a thoroughly and well-equipped medical school in connexion with a great general hospital. It was desirable to urge this inter-connexion between hospital and school because it never seemed to meet with adequate recognition at the hands of the general public who believed that the teaching staff of such schools obtained large pecuniary advantages from them.- Sir William Church then distributed the prizes and among the chief awards were the following: the Kirkes scholarship and gold medal to Mr. C. M. H. Howell; the Brackenbury surgical scholarship to Mr. F. J. Faulder ; the Brackenbury medical scholarship to Mr. C. H. Howell; and the Lawrence scholarship and gold medal to Mr. A. A. Meaden. In the course of a short address Sir William Church said that the interest of their work repaid the students for their exertions and the increase of their knowledge on the causa. tion of disease was an incentive to work. In medicine as distinct from surgery the progress had not been so striking to the public but the advance had really been more remarkable. The complexity of medicine now rendered it impossible for any man to be equally familiar with every branch of medical science and this necessitated the existence of specialists. Votes of thanks to Sir William Church and the chairman closed the proceedings. 